\title{
Adsorptive Recovery of Au(III) from Aqueous Solution Using Modified Bagasse Biosorbent
}

\author{
Theeraporn Rubcumintara
}

\begin{abstract}
The recovery of $\mathrm{Au}$ (III) from aqueous chloride solutions onto modified bagasse biosorbent was investigated. The parameters for biosorbent preparation as well as gold recovery were studied in detail. It was found that $99.8 \%$ of sugarcane bagasse could be modified as biosorbent having better physical properties for adsorption. The solution $\mathrm{pH}$, sorbent dosage, initial $\mathrm{Au}$ (III) concentration and temperature were the studied variables that affect the efficiency of gold recovery as well as adsorption behavior. The efficiency of $99 \%$ for $\mathrm{Au}(\mathrm{III})$ recovery was obtained under the following conditions: $25 \mathrm{mg}$ sorbent, $25 \mathrm{~mL}$ of $25-500 \mathrm{mg} / \mathrm{L} \mathrm{Au}(\mathrm{III}), \mathrm{pH} 2,150 \mathrm{rpm}, 4 \mathrm{~h}$ and $25^{\circ} \mathrm{C}$. The $99 \%$ of gold recovery still obtained in only $1 \mathrm{~h}$ or less with the increasing of dosage or temperature. The gold adsorption in this study was best fitted with Langmuir isotherm model and the maximum capacity for gold loading was determined to be $1497.5 \mathrm{mg} / \mathrm{g}$ or $7.6 \mathrm{mmol} / \mathrm{g}$. The adsorption kinetics was also evaluated in terms of the pseudo first-order and pseudo second-order kinetic models. The high activation energy of $45.8 \mathrm{~kJ} / \mathrm{mol}$ was estimated which represents a chemisorption process. The adsorption mechanism in this study is clarified to be the oxidation of hydroxyl to carbonyl in biosorbent and reduction of trivalent gold ions to metallic gold simultaneously on biosorbent surface. The results from ORP measurement, FT-IR and EDS spectra including SEM images were the supported evidence for this adsorption mechanism. The modified bagasse biosorbent therefore has potential in gold recovery process.
\end{abstract}

Index Terms-Au(III) recovery, modified bagasse, biosorbent.

\section{INTRODUCTION}

Because the primary resource of gold has been declined due to the less abundant on earth crust, the world gold production from mining has then be limited [1]. About one-third of the precious metals available from electronic waste are recorded to be gold, then the secondary resource from used appliances or electronic scraps that has gold as the composition now become the potential source for gold production and can be considered as the major economic driver for recycling of electronic waste [2], [3]. To extract gold from electronic waste, the hydrometallurgical routes such as gold precipitation, ion-ion exchange and solvent extraction has been selected for processing [3]. All the above recovery processes require chemical agents that need further

Manuscript received May 15, 2014; revised July 12, 2014. This work was supported in part by the Department of Chemical Engineering, Faculty of Engineering, Mahidol University.

T. Rubcumintara is with the Department of Chemical Engineering, Faculty of Engineering, Mahidol University, Nakhonpathom, Thailand 73170 (e-mail: theeraporn.rub@ mahidol.ac.th). treatment in the final step. The investigation to develop an environmentally friendly technique for the recovery of gold from electronic waste is still continuing. The separation of metal ions from solutions using biomass materials has gained more attentions due to their availability and cost. In recent years, the growing interest has been focused on the development of biosorbents prepared from plant materials or agricultural wastes as the adsorbent for gold ions [4]-[6]. Many research works are concerned with the utilization of bio-waste to directly prepare the novel adsorption gels which can be performed reductive adsorption of $\mathrm{Au}$ (III) from chloride medium solutions [7]-[19]. These bio-waste materials are generally composed of natural lignocellulosic fibers and tannin containing sufficient polyphenolic groups which have high capability for interaction with heavy metals such as iron and gold. At present, the adsorption technique to recover gold from aqueous solutions using biomass wastes has become the most promising method and gained more interest due to its low cost, high efficiency and eco-friendly method [20]-[24]. Thailand has been known as one of the leading countries for sugar production from sugarcane, massive amounts of bagasse from sugar industry are disposed as biowaste or utilized as raw material for paper industry. This sugarcane bagasse composes of cellulose and lignin which have many hydroxyl and/or polyphenolic groups that can be chemically reacted to produce adsorbent having a good capacity for $\mathrm{Cu}$ (II), Cd (II) and $\mathrm{Pb}$ (II) ions [25]. This work was attempted to prepare the adsorbent from sugarcane bagasse for gold separation, the efficiency of $\mathrm{Au}(\mathrm{III})$ recovery from aqueous chloride solution using the modified bagasse biosorbent as well as adsorption mechanism were investigated in this study.

\section{A. Materials}

Bagasse used in this work is come from sugar plant located at 14/1 Moo 10 Tambon Tamaka, Saengxuto Road, Amphur Tamaka , Kanchanaburi 71120, Thailand. The cellulose content in the bagasse was determined to be $40.1 \%$ (on dry basis). The $\mathrm{Au}(\mathrm{III})$ solutions used in this work were in the form of tetra-chloro complex of $\mathrm{AuCl}_{4}{ }^{-}\left(\mathrm{HAuCl}_{4} \cdot 4 \mathrm{H}_{2} \mathrm{O}\right)$ and all other chemical reagents were of analytical grade.

\section{B. Biosorbent Preparation}

Sugarcane bagasse that washed, oven dried and ground to small size was refluxed with concentrated sulfuric acid for various time and solid liquid ratio at fixed temperature and stirring speed at $100{ }^{\circ} \mathrm{C}$ and $200 \mathrm{rpm}$, respectively. The brown black precipitated product called as modified bagasse biosorbent was neutralized, washed, oven dried and ground to $100-140$ mesh and used as biosorbent for all adsorption experiments. 


\section{Biosorption Experiments}

A given amount $(25 \mathrm{mg}$ ) of modified biosorbent (on dry basis) was added to the gold solutions $(25 \mathrm{~mL})$ at the controlled conditions of initial concentration, $\mathrm{pH}$ and temperature for a given time with the fixed shaking rate at 150 $\mathrm{rpm}$. At the end of adsorption period, the solution mixture was filtered and solid residue was washed and dried in the oven and then characterized using Fourier transform infrared (FT-IR), scanning electron microscope (SEM) and energy dispersive X-ray (EDS). The concentration of remaining gold in residual filtrate was measured by atomic absorption spectroscopy (AAS). The amount of gold adsorption, $q_{t}(\mathrm{mg}$ $\mathrm{Au} / \mathrm{g}$ ) was computed according to Equation (1) where $C_{i}$ and $C_{t}$ are the concentrations of gold in solution $(\mathrm{mg} / \mathrm{L})$ at initial time and at time $t$, respectively; $V$, the volume of solution $(\mathrm{mL})$ and $W$, the dosage of sorbent used (mg). The percentage of gold recovery from solution can also be calculated by Equation (2).

$$
\begin{gathered}
q_{t}=\frac{\left(C_{i}-C_{t}\right) V}{W} \\
\% \mathrm{Au}(\mathrm{III}) \text { recovery }=\frac{\left(C_{i}-C_{t}\right)}{C_{i}} \times 100
\end{gathered}
$$

The effects of solution $\mathrm{pH}$, sorbent dosage, initial $\mathrm{Au}(\mathrm{III})$ concentration and temperature on adsorption capacity as well as the efficiency of gold recovery were also examined. The EDS pattern, SEM images and FT-IR spectra of the biosorbent before and after adsorption as well as oxidation-reduction potential (ORP) were all used to clarify the adsorption mechanism.

\section{RESULTS AND DISCUSSION}

\section{A. Characterization of Modified Biosorbent}

The $99.8 \%$ yield of modified biosorbent can be achieved from the reaction of sugarcane bagasse with concentrated sulfuric acid by using the conditions of bagasse to sulfuric ratio, time, temperature and stirring speed as follows: 1 to 3 $\mathrm{g} / \mathrm{mL}, 6 \mathrm{~h}, 100{ }^{\circ} \mathrm{C}$ and $200 \mathrm{rpm}$, respectively. The cellulose content determined from acid detergent method as well as physical properties from BET analysis of bagasse and modified bagasse biosorbent were characterized as shown in Table 1. Decreasing of cellulose content from 40.1 to $16.8 \%$ from bagasse to modified biosorbent is due to the consumption of hydroxyl group in the cellulose during cross-linking condensation reaction with concentrated sulfuric acid to form brown black solid known as modified biosorbent having higher porosity and surface area. As shown in Fig. 1 with the assignments of the FT-IR absorption band, the main bands observed for bagasse are as follows : O-H stretching at $3406 \mathrm{~cm}^{-1}, \mathrm{C}-\mathrm{H}$ stretching at $2907 \mathrm{~cm}^{-1}$, and O-H bending of absorbed water at $1639 \mathrm{~cm}^{-1}$ [26]. After condensation reaction, the broader band with less intensity of $\mathrm{O}-\mathrm{H}$ stretching is observed at $3442 \mathrm{~cm}^{-1}$. The change of the intensity of the band at $3442 \mathrm{~cm}^{-1}$ which is slightly less broad for bagasse in comparison with broader for bagasse biosorbent suggests this condensation result. The new peaks of biosorbent are shown at 1700 and $1196 \mathrm{~cm}^{-1}$ which represent the $\mathrm{C}=\mathrm{O}$ stretching and $\mathrm{C}-\mathrm{O}-\mathrm{C}$ stretching, respectively. The formation of C-O-C stretching band after condensation reaction of bagasse is the evidence to support that the cross-linking occurs at the hydroxyl group of cellulose [13]. The higher surface area as well as porosity of biosorbent as shown from Table I is consequently resulted from the cross-linking reaction with concentrated sulfuric acid.

TABLE 1: PhysicAl Properties OF SUGARCANE BAGASSE IN COMPARISON WITH MODIFIED BIOSORBENT

\begin{tabular}{|l|c|c|}
\hline \multicolumn{1}{|c|}{ Properties } & Bagasse & Bagasse biosorbent \\
\hline Surface area $\left(\mathrm{m}^{2} / \mathrm{g}\right)$ & 0.9483 & 4.858 \\
\hline Pore volume $\left(\mathrm{cm}^{3} / \mathrm{g}\right)$ & $3.777 \times 10^{-4}$ & $1.752 \times 10^{-3}$ \\
\hline Pore size $(\AA)$ & 67.33 & 133.9 \\
\hline
\end{tabular}

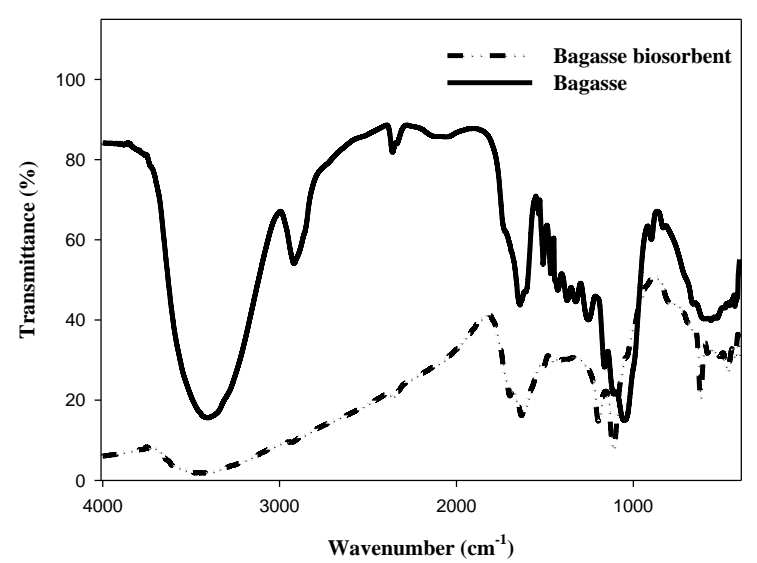

Fig. 1. FT-IR spectra of bagasse before and after modification reaction.

\section{B. Effect of $p H$}

The adsorption experiments at $\mathrm{pH}$ 1, 2, 4 and 6 were carried out to study the effect of solution $\mathrm{pH}$. From the experimental results as shown in Fig. 2, the highest percentage of gold recovery at $99 \%$ was observed at around $\mathrm{pH} 1-2$. When the solution $\mathrm{pH}$ was increased from 4 to 6 , the gold adsorbed decreased rapidly and reached only $56 \%$ for gold recovery at $\mathrm{pH}$ 6. The declining of gold adsorption with increasing of $\mathrm{pH}$ is resulted from the precipitation of chlorogold complex $\left(\mathrm{AuCl}_{4}{ }^{-}\right)$in solutions as $\mathrm{Au}(\mathrm{OH})_{3}$ as shown by Equation 3 [27], [28]. The appearance of gold complex stability strongly depends on the $\mathrm{pH}$ of solutions. The solution $\mathrm{pH}$ for gold adsorption at $\mathrm{pH} 2$ was therefore chosen as suitable $\mathrm{pH}$ for the next experiments.

$$
\mathrm{AuCl}_{4}{ }^{-}+3 \mathrm{H}_{2} \mathrm{O} \rightarrow \mathrm{Au}(\mathrm{OH})_{3}+3 \mathrm{H}^{+}+4 \mathrm{Cl}^{-}
$$

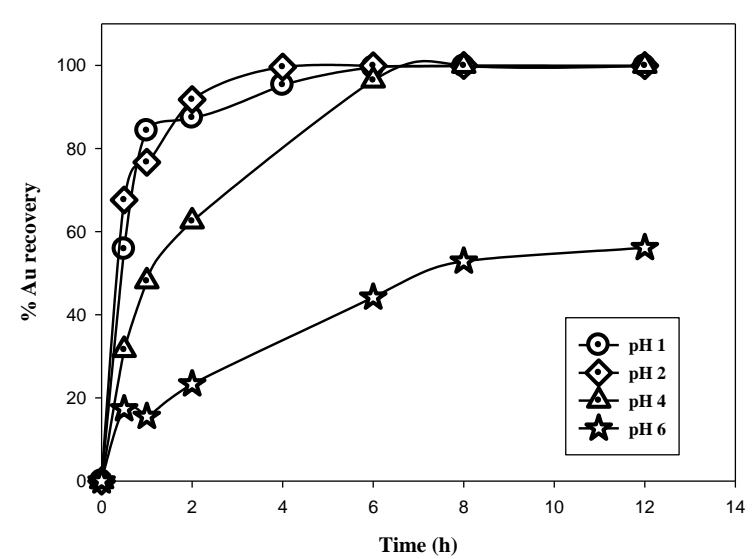

Fig. 2. Effect of $\mathrm{pH}$ on gold recovery.

(Solution volume $25 \mathrm{~mL}$ with initial gold concentration $97.6 \mathrm{mg} / \mathrm{L}$, biosorbent dosage $25 \mathrm{mg}, 25^{\circ} \mathrm{C}, 150 \mathrm{rpm}, 12 \mathrm{~h}$ ) 


\section{Effect of Sorbent Dosage}

The effect of sorbent dosage on gold adsorption and gold recovery was observed, the gold recovery increases with the increase of sorbent dosage as shown in Fig 3a-3b. The adsorption rate as well as \% recovery increased rapidly at initial time and finally reached equilibrium value of $99 \%$ after $1 \mathrm{~h}$ for $35 \mathrm{mg}$ dosage, whereas more than $95 \%$ recovery can be accomplished after $4 \mathrm{~h}$ of contact time using 15-25 mg of dosage. It should be noted that only $30 \%$ of $\mathrm{Au}(\mathrm{III})$ can be recovered with $5 \mathrm{mg}$ of dosage in $6 \mathrm{~h}$ but with the high adsorption capacity. Therefore, to maximize the adsorption capacity, the $1 \mathrm{mg}$ of dosage at $170 \mathrm{~h}$ was used for the next experiment, the result was shown in Fig. 4. The gold loading capacity can be maximized to $1497.5 \mathrm{mg}$ of gold per $\mathrm{g}$ of adsorbent $(7.6 \mathrm{mmol} / \mathrm{g})$.

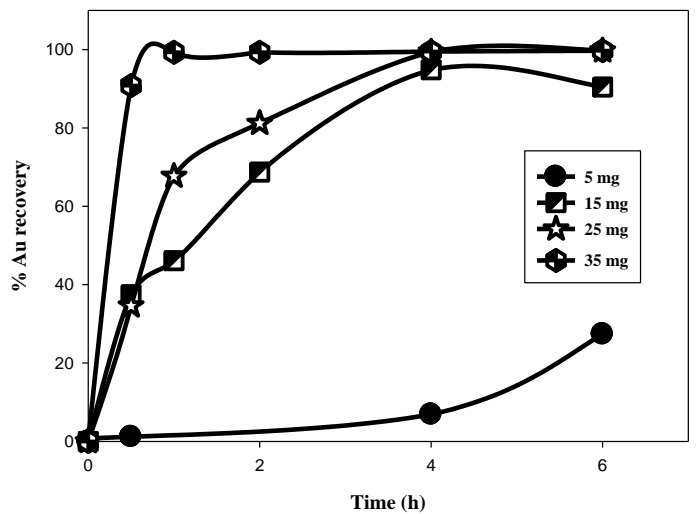

(a)

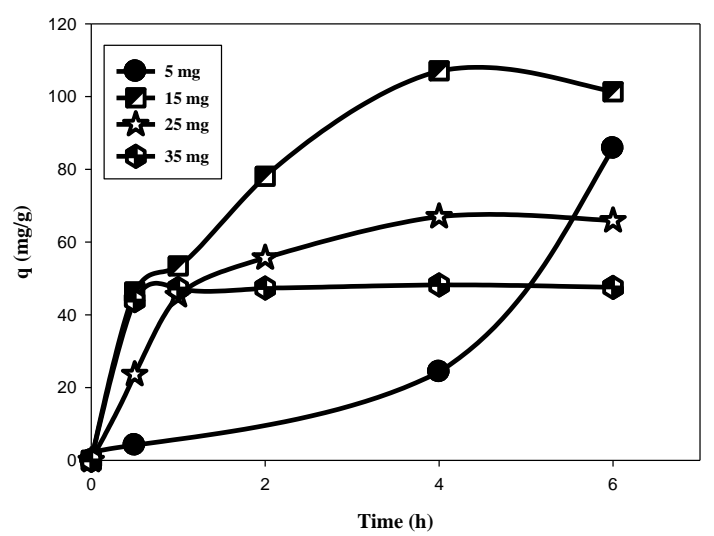

(b)

Fig. 3. Effect of dosage on gold recovery (a) and on gold adsorption capacity (b). ( Solution volume $25 \mathrm{~mL}$ with initial gold concentration 67.7 $\mathrm{mg} / \mathrm{L}$, biosorbent dosage $5-35 \mathrm{mg}, 25^{\circ} \mathrm{C}, 150 \mathrm{rpm}$ ).

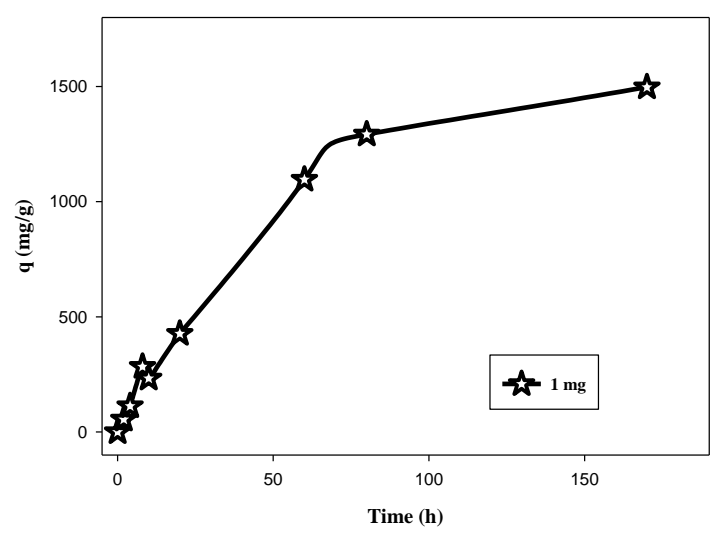

Fig. 4. Effect of contact time on gold adsorption capacity . (Solution volume $25 \mathrm{~mL}$ with initial gold concentration $96.7 \mathrm{mg} / \mathrm{L}$, biosorbent dosage $1 \mathrm{mg}, 25^{\circ} \mathrm{C}, 0 \mathrm{rpm}$ )

\section{Effect of Initial Au(III) Concentration}

The initial $\mathrm{Au}(\mathrm{III})$ concentration of 25, 50, 100, 300, 500 and $800 \mathrm{mg} / \mathrm{L}$ were chosen to be adsorbed by using $25 \mathrm{mg}$ of biosorbent at equilibrium time of $48 \mathrm{~h}$ and at $\mathrm{pH} 2,25^{\circ} \mathrm{C}$, and $150 \mathrm{rpm}$. It was found from the result that the $\mathrm{Au}(\mathrm{III})$ concentration and adsorption capacity at equilibrium $\left(C_{e}\right.$ and $q_{e}$ ) strongly depends on the initial concentration of $\mathrm{Au}(\mathrm{III})$ ions. Equilibrium gold adsorption capacity was increased with the increase of initial $\mathrm{Au}$ (III) concentration from 25 to $800 \mathrm{mg} / \mathrm{L}$. The gold recovery reached almost $100 \%$ for the initial $\mathrm{Au}(\mathrm{III})$ concentration up to $500 \mathrm{mg} / \mathrm{L}$. The results are shown in Table III and Fig. 5 (a) and (b).

TABLE III: EFFECT OF INITIAL AU(III) CONCENTRATION ONTO MODIFIED Biosorbent. (Solution Volume 25 ML, Biosorbent Dosage 25 MG, PH 2, $\left.25^{\circ} \mathrm{C}, 150 \mathrm{RPM}, 48 \mathrm{H}\right)$

\begin{tabular}{|c|c|c|c|}
\hline $\mathbf{A u}(\mathbf{I I I}) \mathbf{m g} / \mathbf{L}$ & $\boldsymbol{C}_{\boldsymbol{e}}(\mathbf{m} / \mathbf{L})$ & $\boldsymbol{q}_{\boldsymbol{e}}(\mathbf{m g} / \mathbf{g})$ & $\%$ Au recovery \\
\hline 25 & 0.096 & 17.38 & 99.6 \\
\hline 50 & 0.014 & 32.83 & 99.9 \\
\hline 100 & 0.205 & 63.39 & 99.8 \\
\hline 300 & 0.395 & 204.30 & 99.9 \\
\hline 500 & 1.023 & 278.96 & 99.7 \\
\hline 800 & 61.4 & 537.85 & 92.6 \\
\hline
\end{tabular}

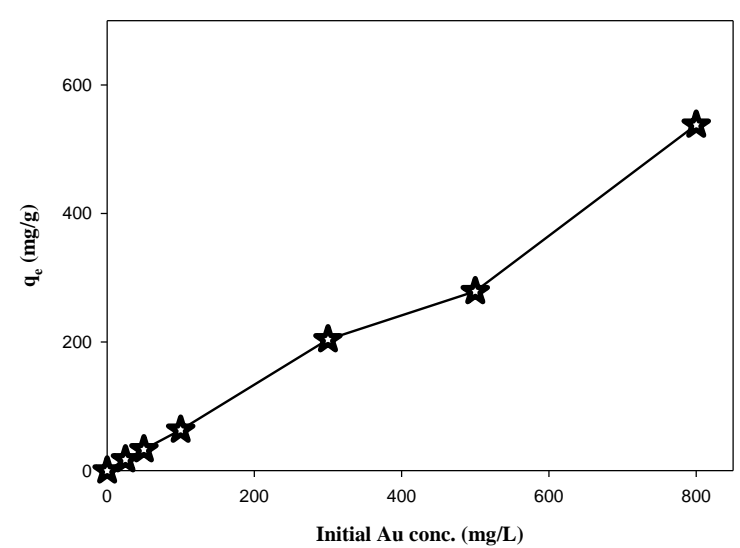

(a)

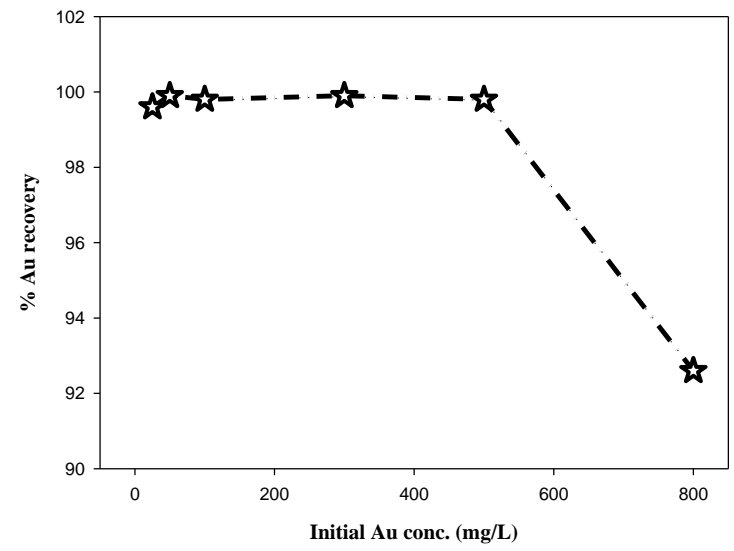

(b)

Fig. 5. Effect of initial concentration on gold adsorption capacity (a) and gold recovery (b). (Solution volume $25 \mathrm{~mL}$ with initial gold concentration 25-800 mg/L, biosorbent dosage $25 \mathrm{mg}, 25{ }^{\circ} \mathrm{C}, 150 \mathrm{rpm}, 48 \mathrm{~h}$ ).

\section{E. Biosorption Isotherm}

In this study, the two commonly used isotherms namely, Langmuir and Frundlich isotherm were applied to explain or predict their equilibrium parameters for $\mathrm{Au}(\mathrm{III})$ adsorption onto biosorbent. The Langmuir model is based on the 
monolayer adsorption on active sites of biosorbent. The Langmuir isotherm can be expressed in the form of non-linear and linear equations as shown in Equations (4) and (5);

$$
\begin{aligned}
q_{e} & =\frac{q_{\max } K_{L} C_{e}}{1+K_{L} C_{e}} \text { (non-linear form) } \\
\frac{C_{e}}{q_{e}} & =\frac{1}{q_{\max } K_{L}}+\frac{1}{q_{\max }} C_{e} \text { (linear form) }
\end{aligned}
$$

where $C_{e}$ is the concentration of $\mathrm{Au}(\mathrm{III})$ solution at equilibrium $(\mathrm{mg} / \mathrm{L}), q_{e}$ and $q_{\max }$ are the equilibrium and maximum of $\mathrm{Au}(\mathrm{III})$ adsorbed at equilibrium $(\mathrm{mg} / \mathrm{g})$, and $K_{L}$ is the Langmuir equilibrium constant which is related to the adsorption energy. The linear plot between $C_{e} / q_{e}$ and $C_{e}$ using data available from Table III was shown in Fig. 6 (a).

The Frundlich isotherm explains the adsorption based on the assumption of multiple layer on heterogeneous surface. The empirical equation and its logarithmic form can be expressed as Equations (6) and (7), respectively.

$$
\begin{gathered}
q_{e}=K_{F} C_{e}^{\frac{1}{n}} \text { (non-linear form) } \\
\log q_{e}=\log K_{F}+\frac{1}{n} \log C_{e} \text { (linear form) }
\end{gathered}
$$

where $K_{F}$ and $n$ are the Frundlich constant related to adsorption capacity of adsorpbent and adsorption intensity, respectively. The values of $K_{F}$ and $n$ can be evaluated from the intercept and slope of the linear plot between $\log q_{e}$ and $\log$ $C_{e}$ as shown in Fig. 6 (b).

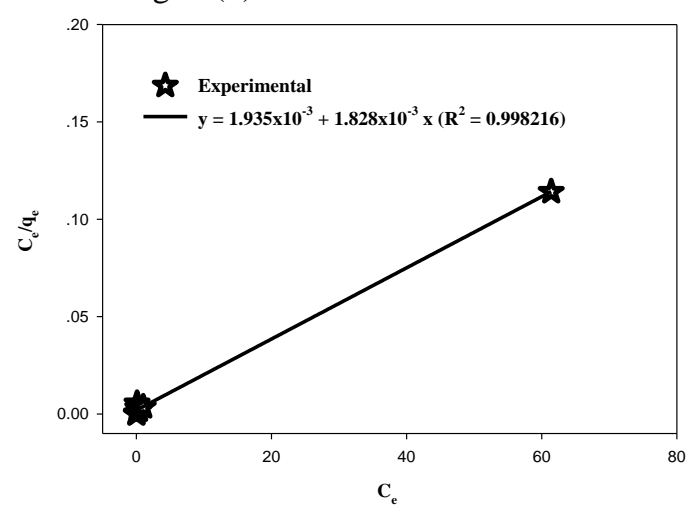

(a)

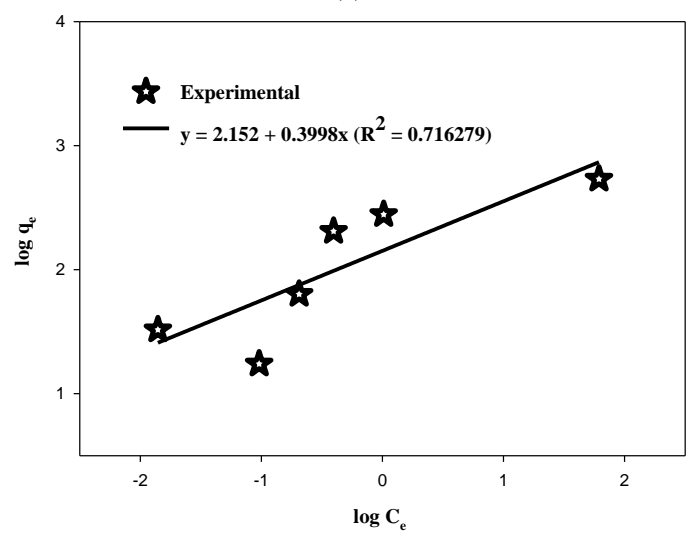

(b)

Fig. 6. The linear plots based on Langmuir isotherm (a) and Frundlich isotherm (b) : (Solution volume $25 \mathrm{~mL}$ with initial gold concentration 25-800 mg/L, biosorbent dosage $25 \mathrm{mg}, \mathrm{pH} 2,25^{\circ} \mathrm{C}, 150 \mathrm{rpm}, 48 \mathrm{~h}$ ).

It was shown from the results of linear plots in Fig. 6 that the $\mathrm{Au}(\mathrm{III})$ adsorption onto biosorbent follows the Langmuir model due to the higher in correlation coefficient value $\left(R^{2}\right)$. This suggests that the monolayer adsorption of $\mathrm{Au}(\mathrm{III})$ dominates on biosorbent surface.

\section{F. Biosorption Kinetics}

The kinetic models for adsorption namely pseudo-first order and pseudo-second order model were considered. The rate of adsorption capacity over the contact time for the first order and second order can be written as Equations (8) and (9). By integrating Equations (8) and (9) using boundary conditions from $t=0$ to $t=t$ and $q_{t}=0$ to $q_{t}=q_{e}$, the equations after rearrangement were shown as Equations 10 and 11 for pseudo-first order and pseudo-second order, respectively.

$$
\begin{gathered}
\frac{d q_{t}}{d t}=k_{1}\left(q_{e}-q_{t}\right) \\
\frac{d q_{t}}{d t}=k_{2}\left(q_{e}-q_{t}\right)^{2} \\
\log \left(q_{e}-q_{t}\right)=\log q_{e}-\frac{k_{1}}{2.303} t \\
\frac{t}{q_{t}}=\frac{1}{k_{2} q_{e}^{2}}+\frac{1}{q_{e}} t
\end{gathered}
$$

where $k_{1}$ and $k_{2}$ are the rate constant of pseudo-first order $\left(\mathrm{min}^{-1}\right)$ and pseudo-second order $\left(\mathrm{kg} \operatorname{mol}^{-1} \min ^{-1}\right)$, respectively. The temperature at $25,35,45$ and $55{ }^{\circ} \mathrm{C}$ were varied for adsorption experiments, the adsorption capacity is increased with time and increased with temperature as observed in Fig. 7. The $R^{2}$ values from the plots of $\log \left(q_{e}-q_{t}\right)$ versus time $t$ in Fig. 8 (a) for each temperature were between 0.94-0.99 which is a little higher than the $R^{2}$ values from the plots of $t / q_{t}$ versus time $t$ represented as pseudo-second order model as shown in Fig. 8(b). The evaluated pseudo-first order rate constants $\left(k_{1}\right)$ for each temperature were then calculated and use in the Arrhenius plot (Equation (12) and Fig. 9). The activation energy of $45.8 \mathrm{~kJ} / \mathrm{mol}$ can be evaluated from the slope of this plot. Chemical adsorption is usually between 8.4-83.7 $\mathrm{kJ} / \mathrm{mol}$ [13]. This reveals that the chemical adsorption dominates in this adsorption process.

$$
\ln k=\ln A-\frac{E_{a}}{R}\left(\frac{1}{T}\right)
$$

where $R$ is the gas constant, $A$ is constant and $E_{a}$ is the activation energy for gold adsorption process.

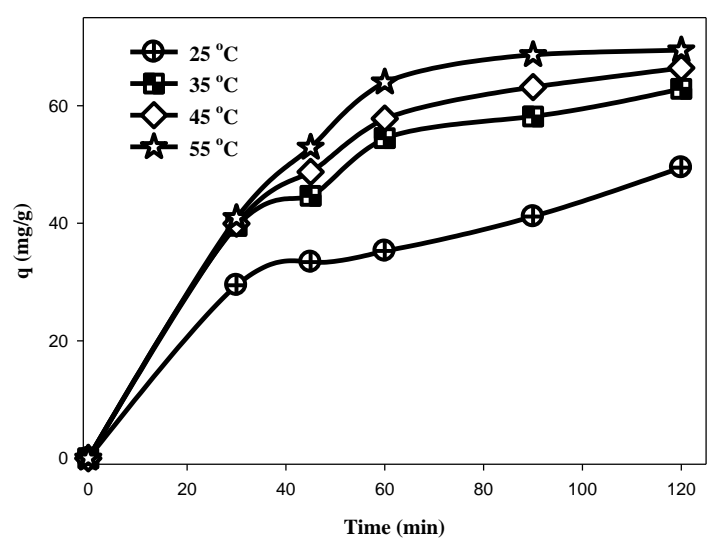

Fig. 7. Effect of contact time on gold adsorption capacity at different temperature. (Solution volume $25 \mathrm{~mL}$ with initial gold concentration 97.6 $\mathrm{mg} / \mathrm{L}$, biosorbent dosage $35 \mathrm{mg}, 25-55^{\circ} \mathrm{C}, 150 \mathrm{rpm}, 3 \mathrm{~h}$ ). 


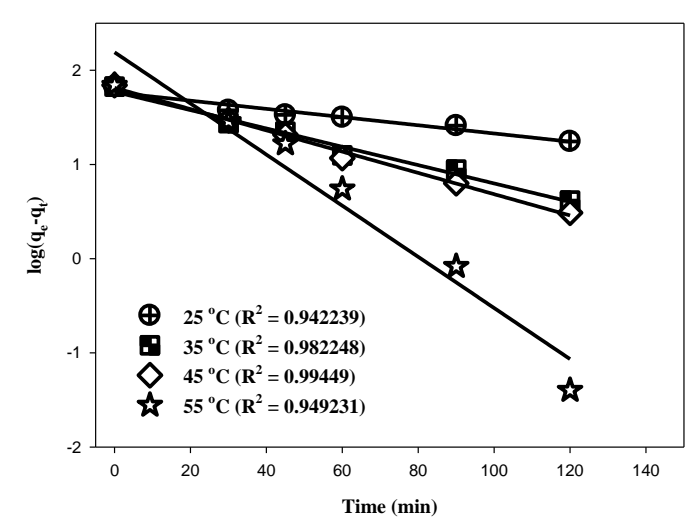

(a)

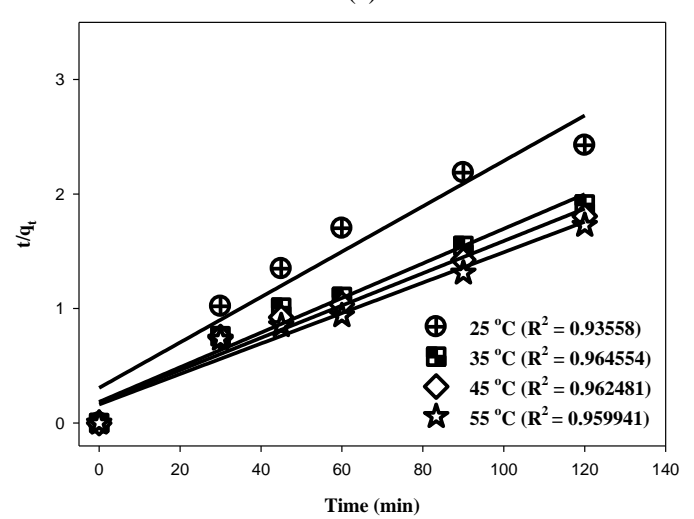

(b)

Fig. 8. Adsorption kinetics of $\mathrm{Au}$ (III) by modified bagasse biosorbent at different temperatures for pseudo-first order (a) and pseudo-second order (b) (Solution volume $25 \mathrm{~mL}$ with initial gold concentration $97.6 \mathrm{mg} / \mathrm{L}$, sorbent dosage $35 \mathrm{mg}, 25-55^{\circ} \mathrm{C}, 150 \mathrm{rpm}, 3 \mathrm{~h}$ ).

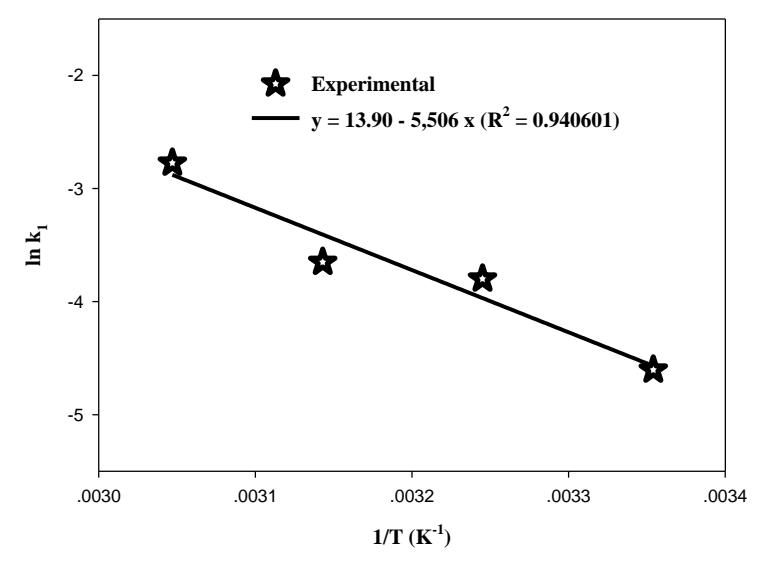

Fig. 9. Arrhenius plot from kinetics data of $\mathrm{Au}(\mathrm{III})$ by modified bagasse biosorbent at different temperatures. (Solution volume $25 \mathrm{~mL}$ with initial $\mathrm{Au}$ (III) concentration $97.6 \mathrm{mg} / \mathrm{L}$, sorbent dosage $35 \mathrm{mg}, 25-55^{\circ} \mathrm{C}, 150 \mathrm{rpm}$, $3 \mathrm{~h})$.

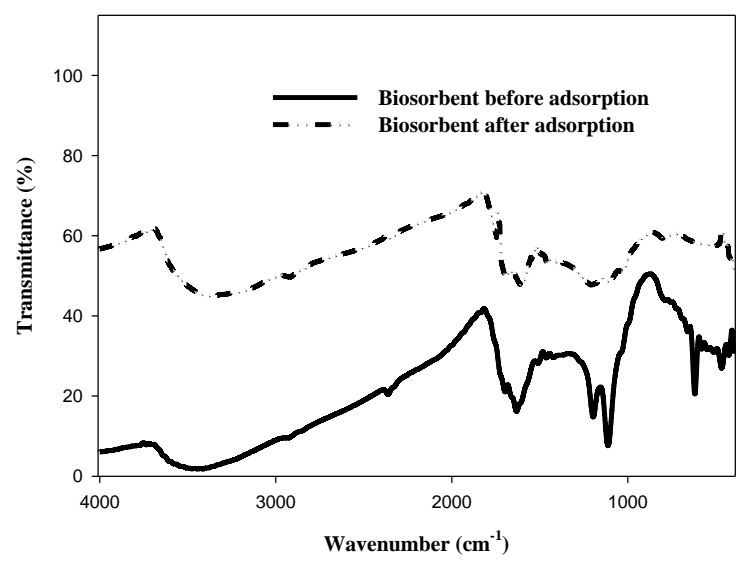

Fig. 10. FT-IR spectra of modified bagasse biosorbent before and after adsorption.

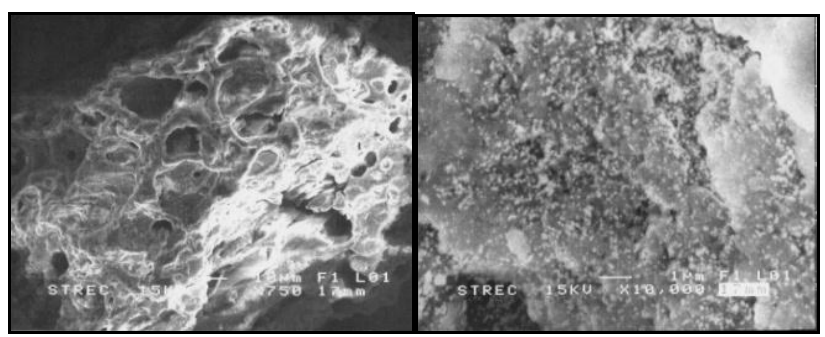

(a) $\times 750$

(b) $\times 10000$

Fig. 11. SEM images of modified bagasse biosorbent after adsorption at different magnification (a for 750 magnification and $b$ for 10,000 magnification) reveals the gold particle on the surface.

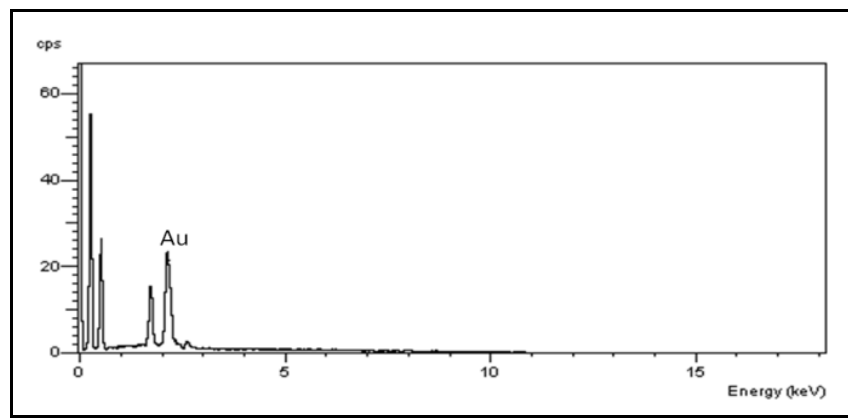

Fig. 12. Elemental gold peak from EDS spectra of modified bagasse biosorbent after adsorption.

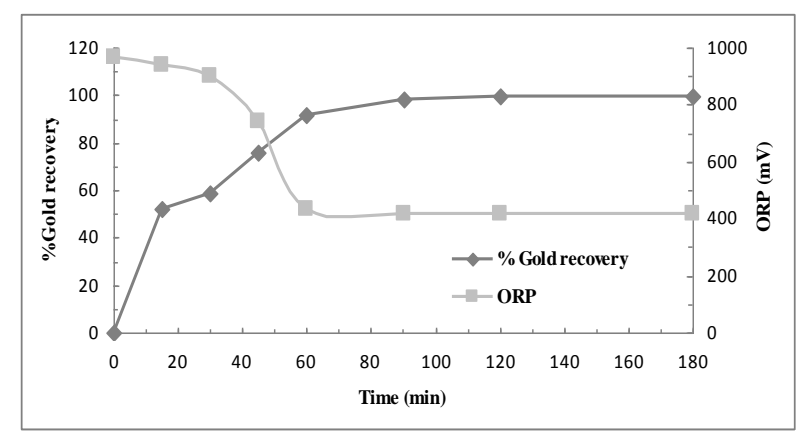

Fig. 13. Oxidation-reduction potental versus time.

(Solution volume $25 \mathrm{~mL}$ with initial gold concentration $97.6 \mathrm{mg} / \mathrm{L}$, biosorbent dosage $35 \mathrm{mg}, 55^{\circ} \mathrm{C}, 150 \mathrm{rpm}$ )

\section{G. Adsorption Mechanism}

The results from FT-IR spectra, SEM images and EDS patterns as shown in Fig. 10-Fig. 12 are confirmed the oxidation of hydroxyl to carbonyl group in biosorbent and the reduction of gold(III) ions that occur simultaneously on the surface of synthesized biosorbent as expressed by Equations 13 and 14 and the overall reaction (Equation (15)). From FT-IR spectra (Fig. 10), the peak for O-H $\left(3442 \mathrm{~cm}^{-1}\right), \mathrm{C}=\mathrm{O}$ $\left(1700 \mathrm{~cm}^{-1}\right)$ and C-O-C $\left(1196 \mathrm{~cm}^{-1}\right)$ bands were shifted after adsorption as shown in Fig. 10. The hydroxyl peak has become broader, the intensity of carbonyl peak has increased and the sharp peak of C-O-C has become less intense and broader. All these appearance are signified that the redox reaction take place on the surface of biosorbent. The hydroxyl group is oxidized to the carbonyl group as well as the binding of Au ions. The other supports came from SEM images (Fig. 11) at 10,000 time of magnification, the metallic gold particle can be observed on the biosorbent surface. The EDS patterns shown in Fig. 12 is the supportive evidence for the appearance of gold in metallic form on biosorbent after adsorption.

$$
\begin{array}{r}
\mathrm{R}-\mathrm{OH} \rightarrow \mathrm{R}=\mathrm{O}+\mathrm{H}^{+}+\mathrm{e}^{-} \\
\mathrm{AuCl}_{4}^{-}+3 \mathrm{e}^{-} \rightarrow \mathrm{Au}^{0}+4 \mathrm{Cl}^{-}
\end{array}
$$




$$
\mathrm{AuCl}_{4}^{-}+3 \mathrm{R}-\mathrm{OH} \rightarrow \mathrm{Au}^{0}+4 \mathrm{Cl}^{-}+3 \mathrm{R}=\mathrm{O}+3 \mathrm{H}^{+}
$$

Fig. 13 shows that the measurement of oxidation- reduction potential or ORP as a function of time, the decrease of ORP in the first hour indicates the reduction of gold ions in solution to metallic gold and then level off after one hour which is coincided with the maximum percentage of gold recovery after one hour of adsorption.

\section{CONCLUSION}

It can be concluded from this investigation that sugarcane bagasse can be modified by the reaction with concentrated sulfuric acid to produce biosorbent for gold recovery effectively. The $99 \%$ gold recovery was accomplished when using the initial gold concentration in the range from 25 to $500 \mathrm{mg} / \mathrm{L}$. The adsorption behavior represent Langmuir model. The activation energy of $45.8 \mathrm{~kJ} / \mathrm{mol}$ suggests that the adsorption process is chemically control. The adsorption mechanism was elucidated to be the oxidation of hydroxyl group to carbonyl group in synthesized biosorbent and reduction of $\mathrm{Au}(\mathrm{III})$ on the surface of adsorbent simultaneously. The sugarcane bagasse might be the low cost material for gold recovery as the alternative choice.

\section{ACKNOWLEDGMENT}

The author would like to thank Tamaka Sugar Industry Co. Ltd. and the Department of Chemical Engineering, Faculty of Engineering , Mahidol University for raw materials, chemical agents and laboratory support.

\section{REFERENCES}

[1] U. S. Geological Survey. Gold Statistics. [Online]. Available: http://minerals.usgs.gov/minerals/pubs/historical-statistics/ds140-gol d.pdf Retrieved 2014-04-30

[2] H. Y. Kang and J. M. Schoenung, "Electronic waste recycling: A review of U.S. infrastructure and technology options," Resour Conserv Recy., vol. 45, pp. 368-400, 2005.

[3] J. Cui and L. Zhang, "Metallurgical recovery of metals from electronic waste : A review," J. Hazard. Mate, vol. 158, pp. 228-256, 2008.

[4] C. Mack, B. Wilhelmi, J. R. Duncan, and J. E. Burgess, "Biosorption of precious metals: Research review paper," Biotechnol Adv., vol. 25, pp. 264-271, 2007

[5] A. Demirbas, "Heavy metal adsorption onto agro-based waste materials: A review," J. Hazard. Mater, vol. 157, pp. 220-229, 2008.

[6] N. Das, "Recovery of precious metals through biosorption : A review," Hydrometallurgy., vol. 103, pp. 180-189, 2010.

[7] D. Parajuli, H. Kawakita, K. Inoue, K. Ohto, and K. Kajiyama, "Persimmon peel gel for the selective recovery of gold," Hydrometallurgy., vol. 87, pp. 133-139, 2007.

[8] C. Tasdelen, S. Aktas, E. Acma, and Y. Guvenilir, "Gold recovery from dilute gold solutions using DEAE-cellulose," Hydrometallurgy, vol. 96, pp. 253-257, 2009.

[9] D. Parajuli, C. R. Adhikari, H. Kawakita, S. Yamada, K. Ohto, and K. Inoue, "Chestnut pellicle for the recovery of gold," Biores Technol, vol. 100, pp. 1000-1002, 2009.

[10] M. Sathishkumar, A. Mahadevan, K. Vijayaraghavan, S. Pavagadhi, and R. Balasbramanian, "Green recovery of gold through biosorption, biocrytallization, and pyro-crystallization," Ind. Eng. Chem. Res., vol. 49, pp. 7129-7135, 2010.

[11] M. Gurung, B. Adhikari, H. Kawakita, K. Ohto, and K. Inoue, "Recovery of $\mathrm{Au}(\mathrm{III})$ by low cost adsorbent prepared persimmon tannin extract," Chem. Eng. J., vol. 174, pp. 556-563, 2011.
[12] K. Vijayaraghavan, A. Mahadevan, M. Sathishkumsr, S. Pavagadhi, and R. Balasubramanian, "Biosynthesis of $\mathrm{Au}(0)$ from $\mathrm{Au}(\mathrm{III})$ via biosorption and bioreduction usng brown marine alga," Turbinaria conoides, Chem. Eng. J., vol. 167, pp. 223-227, 2011.

[13] B. Pangeni, H. Paudyal, K. Inoue, H. Kawakita, K. Ohto, and S. Alam, "An assessment of gold recovery processing using cross-linked paper gel," J. Chem. Eng. Data., vol. 57, pp. 796-804, 2012.

[14] P. Lodeiro and M. Sillanpaa, "Gold reduction in batch and column experiments using silica gel derivates and seaweed biomass," Chem. Eng. J., vol. 230, pp. 372-379, 2013.

[15] X. Li, C. Zhang, R. Zhao, X. Lu, X. Xu, X. Jia, C. Wang, and L. Li, "Efficient adsorption of gold ions from aqueous systems with thioamide-group chelating nanofiber-membranes," Chem. Eng. J., vol. 229, pp. 420-428, 2013.

[16] B. Adhikari,M. Gurung, S. Alam, B. Tolnai, and K. Inoue, "Kraft mill lignin - A potential source of bio-adsorbents for gold recovery from acidic chloride solution," Chem. Eng. J., vol. 231, pp. 190-197, 2013.

[17] M. Gurung, B. Adhikari, X. Gao, S. Alam, and K. Inoue, "Sustainability in the metallurgical industry: Chemically modified cellulose for selective biosorption of gold from mixtures of base metals in chloride media," Ind. Eng. Chem. Res.., vol. 53, no. 20, pp. 8565-8567, 2014.

[18] R. Fan, F. Xie, X. Guan, Q. Zhang, and Z. Luo, "Selective adsorption and recovery of $\mathrm{Au}(\mathrm{III})$ from three kinds of acidic systems by persimmon residual based bio-sorbent: A method for gold recycling from e-waste," Biores. Technol., vol. 163, pp. 167-171, 2014.

[19] M. Jaishankar, B. Mathew, M. Shah, K. Murthy, and S. Gowda, "Biosorption of few heavy metal ions using agricultural wastes," $J$. Environ. Poll. Heal., vol. 2, pp. 1-6, 2014.

[20] M. Abidin, A. Jalil, S. Triwahyono, S. Adam, and N. Kamarudin, "Recovery of gold (III) from an aqueous solution onto a durio zibethinus husk," Biochem. Eng. J., vol. 54, pp. 124-131, 2011.

[21] N. Feng, X. Guo, S. Liang, Y. Zhu, and J. Liu, "Biosorption of heavy metals from aqueus solutions by chemically modified orange peel," $J$. Hazard. Mater., vol. 185, pp. 49-54, 2011.

[22] X. Chen, K. Lam, S. Mak, and K. Yeung, "Precious metal recovery by selective adsorption using biosorbents," J. Hazard. Mater., vol. 186, pp. 902-910, 2011.

[23] S. Park, I. S. Kwak, M. Bae, J. Mao, S. Won, Do H. Han, Y. S. Chung, and Y. Yun, "Recovery of gold as a type of porous fiber by using biosorption followed by incineration," Biores. Technol., vol. 100, pp. 208-214, 2012.

[24] M. Gurung, B. Adhikari, S. Alam, H. Kawakita, K. Ohto, and K. Inoue, "Persimmon tannin-based new sorption material for resource recycling and recovery of precious metals," Chem. Eng. J., vol. 228, pp. 405-414, 2013.

[25] O. Karnitz Jr, L.V. A. Gurgel, J. C. P. D. Melo, V. R. Botaro, T. M. S. Melo, R. P. D. F. Gil, and L. R. Gil, "Adsorption of heavy metal ion from aqueous single metal solution by chemically modified sugarcane bagasse," Biores Technol, vol. 98, pp. 1291-1297, 2007.

[26] V. Agarwal, G. W. Huber, W. C. Conner Jr, and S. M. Auerbach, "Simulating infrared spectra and hydrogen bonding in cellulose I $\beta$ at elevated temperature," J. Chem. Phys, vol. 135, 2011.

[27] C. L. Mantel, Electrochemical Engineering, McGraw Hill, 1960.

[28] R. R. Winston, Uhlig's Corrosion Handbook, John Wiley \& Sons, Inc., 2000.

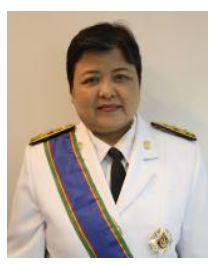

Theeraporn Rubcumintara earned her bachelor degree in chemistry from Chiangmai University, Thailand in 1978 and obtained M.S. in metallurgical engineering as well as Ph.D. in materials engineering \& science from South Dakota School of Mines \& Technology, Rapid City, South Dakota, USA in 1985 and 1989, respectively. At present, she is an assistant professor of Chemical Engineering Department, Mahidol University, Thailand. Her research area is in the field of metal extraction and recycling. She is a member of Thailand Insitute of Chemical Engineering and Applied Chemistry (TIChE) and has been the member of The Minerals, Metals, and Materials Society (TMS) since 1989. 